\title{
A Note on Spelling
}

Portuguese: I have modernized all Portuguese spellings in the text and footnotes except for book titles. Any exceptions to this rule are noted.

Yiddish: I have used the modern (YIVO) transliteration system for all Yiddish words except for those newspapers in which a transliteration appears on the masthead. In those cases I have reproduced the transliteration faithfully. 